\title{
LA CONQUISTA DEL PODER POLÍTICO POR EL LIBERALISMO MEXICANO, 1824-1876
}

\section{Emilio Martínez Albesa* \\ Pontificio Ateneo Regina Apostolorum - Universidad Europea de Roma}

Fecha de recepción: agosto de 2012 Fecha de aceptación: octubre de 2012

Resumen: La vida política de México durante sus primeros decenios de vida independiente aparece inestable y confusa. Este estudio presenta una síntesis concisa e inteligible de este recorrido histórico, atendiendo a los hechos y a las ideas. En él, se analizan la configuración del pensamiento político del liberalismo mexicano, su concreción en un partido político y su ascenso al poder.

Palabras clave: liberalismo, México, Reforma, conservadurismo, yorkino, escocés, Mora, Alamán, Bustamante, Otero, Zarco, Mata, Juárez

* Emilio Martínez Albesa es doctor en Historia de América por la Universidad Complutense de Madrid y doctor en Historia Eclesiástica por la Pontificia Universidad Gregoriana. Es profesor estable de la Facultad de Teología del Pontificio Ateneo Regina Apostolorum y docente de la licenciatura en Ciencias Históricas de la Universidad Europea de Roma. Miembro del Consejo directivo del Foro Hispanoamericano Francisco de Vitoria (Universidad Francisco de Vitoria, Madrid). Autor, entre otras publicaciones, de la obra La Constitución de 1857. Catolicismo y liberalismo en México (3 vols., Porrúa, 2007). Ha sido coordinador del Congreso internacional de investigación histórica La Iglesia ante la independencia de la América española, celebrado con motivo del bicentenario en la Ciudad del Vaticano y Roma (abril de 2010), con el patrocinio del Pontificio Consejo de la Cultura y la Pontificia Comisión para América Latina y organizado por las universidades en las que él enseńa. 
AвSTRACT: The political life of Mexico during its first decades of independent life appears unstable and confusing. This study presents a concise and intelligible synthesis of this historical process, considering the facts and the ideas. It analyzes the configuration of the political thought of the Mexican liberalism, its materialization in a political party and its rise to power. Kerwords: liberalism, Mexico, Reform, Conservatism, yorkino, escocés, Mora, Alamán, Bustamante, Otero, Zarco, Mata, Juárez

\section{LOS PRIMEROS PARTIDOS POLÍTICOS (1824-1834)}

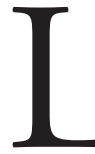

a rivalidad entre las facciones políticas habría de caracterizar la vida de la primera República federal mexicana. Durante la presidencia de Guadalupe Victoria (1824-1829), dos facciones se disputarán los puestos en el gabinete de gobierno y en el congreso: la de los escoceses, alrededor de Nicolás Bravo, y la de los yorkinos, alrededor de Vicente Guerrero. El enfrentamiento tendrá por escenario, además de la administración pública, la prensa y la calle, con movilizaciones y pronunciamientos. Existirá un debate ideológico; pero las afiliaciones políticas no estarán determinadas por él, sino que de momento pesarán más los intereses personalistas y de grupo (Cf. Costeloe 1983; Hale 1972). El año 1825 corrió bajo signo escocés. El grupo político de los escoceses había nacido de la antigua masonería de aquel rito vinculada originariamente a los españoles liberales (Cf. Mora 1837: 12-13) y, ahora, reunía a centralistas y miembros de la élite política nacida de la independencia. Entre los escoceses, estaban José María Luis Mora, Florentino Martínez, José María Cabrera, Melchor Múzquiz, Miguel Barragán, Francisco Manuel Sánchez de Tagle, José Antonio Facio, Sebastián Camacho y Lucas Alamán. Al final del verano 
de ese año, se fundaron cinco logias masónicas de rito yorkino en la ciudad de México (dependientes de la Gran Logia de Nueva York), apadrinadas por el intrigante representante de Estados Unidos Joel R. Poinsett (1759-1853), con el objeto de cambiar el signo político del gobierno. Sus fundadores Lorenzo de Zavala (senador), Miguel Ramos Arizpe (funcionario del ministerio de Justicia), José Ignacio Esteva (ministro de Hacienda), el cura tabasqueño José María Alpuche Infante (senador). En el bando yorkino se reunirán los enemigos de los escoceses y miembros de las élites locales de los Estados y de otros nuevos grupos ascendentes. Además de los fundadores, yorkinos eran, entre otros, José María Tornel (secretario personal de Victoria, luego santanista), Anastasio Zerecero, Anastasio Bustamante (1780-1853) y Manuel Gómez Pedraza (1789-1851) y contaban con la simpatía de Juan José Espinosa de los Monteros. El grupo yorkino (también llamado popular y americano) tomó la bandera del federalismo, del pueblo y de la independencia, aduciendo que los escoceses ponían en peligro todo estos valores por su favoritismo hacia los españoles. Para finales de 1825, los yorkinos habrían ganado mucha influencia y, en las poco limpias elecciones de 1826 para el congreso de 1827, lograrían un notable triunfo. En 1827, el grupo yorkino se fortaleció mediante una campaña populista antiespañola, tomando pie de la conspiración del religioso español Joaquín Arenas, que condujo a la ley de expulsión de los españoles del 20 de diciembre. En el mismo año nacieron otros tres grupos políticos: el de los novenarios, creado por algunos líderes escoceses — como Bravo, Barragán, Mora y Rejón—, el de los guadalupanos, nacido de los yorkinos, y el de los imparciales, disidentes yorkinos decepcionados — como Ramos Arizpe y Tornel-y algunos otros - como Valentín Gómez Farías-. El fracaso de la sublevación escocesanovenaria de Tulancingo, protagonizada por Bravo en diciembre de ese año, abrió las puertas del poder a los yorkinos. Durante 1828, los radicales y 
populistas yorkinos encuentran la oposición del grupo aglutinado en torno a su disidente Gómez Pedraza y de los pujantes imparciales. Las elecciones presidenciales de septiembre de 1828 dan el triunfo a Gómez Pedraza; pero el pronunciamiento de Antonio López de Santa Anna, gobernador de Veracruz, con el plan de Perote, y el motín de la Acordada en la ciudad de México, con la jefatura de Lorenzo de Zavala, rechazan el resultado y obtienen que, a finales de diciembre, Gómez Pedraza renuncie a recibir el puesto. El 12 de enero de 1829 el Congreso declara inválida la elección de éste y nombra presidente al candidato yorkino Vicente Guerrero y vicepresidente a Anastasio Bustamante, quienes habrían de entrar en ejercicio de sus cargos el 1 de abril. Aunque Guerrero tenía un talante conciliador, la rivalidad entre las tres facciones políticas de yorkinos, escoceses-imparciales y hombres de bien (moderados) se enconó durante su mandato. Sus ministros fueron José María Bocanegra (Relaciones), Lorenzo de Zavala (Hacienda), José Manuel Herrera (Justicia y Negocios eclesiásticos) y Francisco Moctezuma (Guerra) (Cf. Bocanegra 1892: 63). ${ }^{1}$ En esta época, los elementos ideológicos, unidos a proyectos sociopolíticos, comienzan a colorear cada vez más las rivalidades políticas. El grupo yorkino consigue que se aplique con más rigor una nueva ley de expulsión de españoles (20 de marzo de 1829). Sus tradicionales enemigos obtendrán la dimisión de Zavala y la expulsión del embajador de Estados Unidos Joel Poinsett. El radicalismo yorkino, que propone reformas populistas y anticlericales, alerta al nuevo grupo de los llamados hombres de bien, que reúnen además a ex partidarios de Gómez Pedraza. En un ambiente de inquietud, habiéndose producido ya un golpe militar a favor del centralismo en Yucatán, el pronunciamiento del plan de Jalapa (4 de diciembre de 1829) conducirá a la caída de Guerrero y a la toma del mando

1 Aunque hubo otros ministros, la mayor parte del período fueron los indicados. 
del ejecutivo por parte del vicepresidente Anastasio Bustamante, que debía gobernar hasta terminar el periodo que habría correspondido a Gómez Pedraza. Era el triunfo de los llamados hombres de bien.

Durante los gobiernos del vicepresidente Anastasio Bustamante (1 de enero de 1830- 14 de agosto de 1832) y del vicepresidente Valentín Gómez Farías (1 de abril de 1833-24 de abril de 1834, con interrupciones), tomarán forma sucesivamente por vía de oposición al gobierno las facciones políticas liberal y conservadora (partido liberal y partido conservador), cuyo antagonismo, bajo las respectivas banderas de progreso y libertad y de orden y legitimidad, habrá de caracterizar la historia política mexicana hasta 1867 (Cf. Bocanegra 1892: 200).

El gabinete gubernamental de Bustamante estuvo formado principalmente por Lucas Alamán (Relaciones), José Ignacio Espinosa (Justicia y Negocios eclesiásticos), José Antonio Facio (Guerra) y Rafael Mangino (Hacienda) (Cf. Bocanegra 1892: 225). Este gobierno acabar con la debilidad que, desde la independencia, padecía el gobierno supremo de la nación, enfrentándose con decisión a la oposición que pudiera hacérsele mediante vías extra constitucionales, como las presiones de facciones rivales y los pronunciamientos militares. Esto sería sentido como un amago de dictadura por los grupos políticos litigantes durante ya un decenio de vida independiente. Vicente Guerrero puso en marcha una revolución en el sur, desconociendo al gobierno en marzo de 1830. San Luis Potosí encabezó pronto una coalición de Estados que decía defender las instituciones, pero que pretendía evitar que el intervencionismo del gobierno federal restase poder a las élites locales. Ante toda esta oposición, el gobierno demostró estar dispuesto a utilizar la fuerza con una determinación a la que no estaban acostumbrados los protagonistas de la vida política mexicana. El fusilamiento del ex presidente Guerrero (14 de febrero de 1831) sería la muestra más 
elocuente del grado de esta determinación. Los ideólogos liberales, que se habían mantenido a la expectativa en los primeros meses, se pondrán de parte de la oposición cuando constaten que el orden que el gobierno busca establecer no es el que ellos desean. Así, aportarán a la oposición política el arma de la llamada ideología progresista, la propia de los liberales de partido, quienes se arrogarían la misión de velar por el nuevo régimen liberal. En contrapartida, el gobierno de Bustamante o administración Alamán, como también se le conocerá, carecerá de una ideología que haga de los hombres de bien una coalición política capaz de enfrentarse a la facción liberal, a pesar de sus evidentes logros en el progreso económico de la sociedad, la reorganización del ejército y la normalización de la vida eclesiástica, tres apremiantes necesidades nacionales. Estos logros alarmarían a los opositores del gobierno, interpretándolos como un favoritismo hacia la sociedad tradicional corporativa organicista y una amenaza para los principios del liberalismo, para los intereses de la facción ahora liberal y para el sistema federalista.

La revolución del plan de Veracruz (2 de enero y 5 de julio de 1832), liderada por Antonio López de Santa Anna (general de división desde su triunfo sobre la expedición española de Isidro Barradas en septiembre de 1829) trajo a finales de 1832 la victoria de los antiguos yorkinos, algunas élites de los Estados y los políticos liberales sobre el gobierno de Bustamante y el de Melchor Múzquiz, no sin antes tener que impugnar los resultados de unas elecciones presidenciales. El acuerdo de Zavaleta entre Gómez Pedraza, López de Santa Anna, Bustamante, Ramos Arizpe y Bernardo González Angulo (23 de diciembre de 1832) estipuló que se convocarían nuevas elecciones para las legislaturas de los Estados, el congreso general y la presidencia y que Gómez Pedraza ejercería la presidencia hasta concluir su período el 31 de marzo. El 1 de abril de 1833 entró en gobierno interino 
de la República el vicepresidente Valentín Gómez Farías, aunque el nuevo presidente era López de Santa Anna. Nada mejor que la curiosa ley del caso (23 de junio de 1833) para ejemplificar la actitud despótica del nuevo gobierno, que nacía de una revolución contra el supuesto carácter dictatorial del de Bustamante: por ella se expulsaba de la República a cincuenta personas allí mencionadas, a los religiosos españoles y a cuantos tuvieren a bien desterrar los Estados, añadiendo en su segundo artículo que en adelante el gobierno podría expulsar además a todos quienes se encontraran en el mismo caso, el cual no se definía en ninguna parte. La oposición al gobierno del liberal Gómez Farías favorecería la constitución de un grupo político de ideología conservadora. Así, las medidas reformistas del gobierno sobre los asuntos eclesiásticos del gobierno harán levantarse contra él a la oposición bajo el lema de «religión y fueros» y López de Santa Anna destituirá al vicepresidente y su equipo en abril de 1834 (Cf. Costoloe 1983: 249-325).

La formación de las facciones políticas rivales liberal y conservadora se produce dentro del régimen político del liberalismo tal como lo hemos descrito anteriormente. Estas facciones no cuestionan dicho régimen político. Su oposición se presenta como una oposición ideológica en la cual los liberales juzgan en peligro los principios de dicho régimen y los conservadores juzgan en peligro los principios de identidad de la nación. Piedra de toque para la división entre ellos fue precisamente la cuestión eclesiástica. En la década de 1840, encontraremos estas dos facciones constituidas en partidos políticos propiamente dichos, es decir, formaciones con miembros clara y explícitamente encuadrados en ellas, organizadas para obtener el gobierno, con un conjunto de iniciativas y principios propios, animadas por una cierta ideología y unos intereses, si bien todavía por largo tiempo bajo un fuerte personalismo y carentes de la rígida organización y disciplina interna que adquirirán más adelante. 
En los primeros ańos 30, el anticlericalismo comenzó a ser bandera política de los liberales reformistas mexicanos, por considerar el influjo de la Iglesia en la sociedad como el principal obstáculo para hacer de ésta una sociedad acorde a sus principios. Los pensadores liberales decepcionados del constitucionalismo elaborarían una ideología reformista en la que el anticlericalismo ocuparía un lugar esencial, y muchos liberales la habrían de aceptar por pragmatismo político. En la capital de la República, los principales órganos de la prensa ideológica liberal esos primeros años fueron «Correo de la Federación Mexicana» (1826-1830), «El Fénix de la Libertad» (1831-1834) y «La Columna de la Constitución Federal de la República Mexicana»(1832-1833).

El liberalismo de facción o de partido se caracteriza por la tendencia a reformar la sociedad con el fin de dotar a sus individuos de una mayor autonomía entre ellos y apoya sobre una aceptación entusiasta de los principios del nuevo régimen liberal que tiende a excluir la posibilidad de considerar otros principios en la política. Se denomina también liberalismo $\stackrel{\infty}{\neg}$ reformista o progresista. El contenido concreto de su tendencia a la reforma en pro de la autonomía individual vendrá definido en cada caso por los diversos partidos o facciones políticas que la asuman. Fundamentalmente, son tres los elementos que constituyen este liberalismo: la tendencia a enfatizar la libertad individual en la definición del hombre; la predisposición al relativismo moral por desconfiar de que exista un bien universalmente válido, con el consecuente oscurecimiento del concepto de bien común, y la proclividad hacia el utilitarismo y filosofía del bienestar. Con esto y sobre la base del régimen liberal contractualista, el Estado pasa a ser visto como una gran máquina utilitarista que debe conducir a la nación a su plena realización como conjunto de individuos felices. El liberalismo de facción toma como bandera el ideal del Estado de nuevo régimen y, por tanto, busca 
transformar la sociedad para adecuarla a ese ideal. No es ya el Estado quien debe adaptarse a la sociedad, sino la sociedad la que ha de transformarse a instancias del Estado con la esperanza de llegar a ser una sociedad de individuos felices. La felicidad de los individuos habrá de llegar gracias a una independencia respecto de los demás que les permita alcanzar sus deseos y, por ello, el progreso material es un medio para obtener independencia. En consecuencia, el Estado deberá liberar al individuo de los vínculos sociales que obstaculicen su autodeterminación; de aquí, su intervencionismo sobre los demás cuerpos sociales que median entre él y el individuo. Un Estado así queda como un instrumento de poder a disposición de la lógica o la ideología de la facción que lo domine. Dentro del liberalismo de partido hemos de distinguir dos corrientes, la radical o pura y la moderada; aunque ambas comparten el objetivo de reformar la sociedad en pro de un mayor individualismo o autonomía de las personas y el gusto por el calificativo de progresista, divergen en los medios a utilizar. Los radicales buscarán imponer un cambio rápido mediante la fuerza del Estado, aun a costa de proceder contra la opinión de los miembros de la sociedad. Los moderados buscarán fomentar también el cambio social desde el Estado, pero, abiertos al diálogo efectivo con los intereses de las distintas partes de la sociedad, buscarán proceder gradualmente, sin prisas, al ritmo que la misma sociedad vaya pudiendo acoger las novedades sin traumatismos.

El principal ideólogo del liberalismo de facción en México fue José María Luis Mora (1794-1850), doctor en teología desde el 26 de julio de 1820. Del sacerdocio, pasó a la política, abandonando para siempre el ejercicio del ministerio eclesiástico algún año después de la independencia. Durante la década de 1820, participando en el grupo borbonista y escocés, destaca por su labor periodística a favor de los principios del nuevo régimen liberal, con sus artículos en el «Semanario político y literario» (1821- 
1822) y «El Observador de la República Mexicana» (1827-1828 y 1830), así como con su Catecismo politico de la Federación Mexicana (entre 1829 y 1831). Estudioso de Benjamin Constant, Jeremy Bentham, el barón de Montesquieu, Gaspar Melchor de Jovellanos y Francisco Javier Martínez Marina, es posiblemente el mexicano que más profundizó en el pensamiento político liberal. En el umbral de los años 30, pasa a defender el reformismo sobre el constitucionalismo, inaugurando el liberalismo de facción (Cf. Martínez 2007: 852-876 y 914-948; Hale 1972; Escobar 1974). Sus ideas y sus propuestas estarán a la base de la reforma de Valentín Gómez Farías de 1833-1834 y las difundirá mediante el periódico «El Indicador de la Federación Mexicana»(1833-1834). Con su Disertación sobre la naturaleza y aplicación de las rentas y bienes eclesiásticos (México 1833), abrió las puertas al anticlericalismo reformista mediante un análisis utilitarista del papel del clero. Tras la caída del gobierno de Gómez Farías, huyó del país el 6 de diciembre de 1834 huye del país. Nunca regresaría; primero el miedo y finalmente un cierto acomodo, logrado después de muchas penurias, le disuadieron de hacerlo. En Europa, publicó sus dos obras principales: Méjico y sus revoluciones (3 tomos, París 1836), inconclusa, de carácter histórico, y la miscelánea Obras Sueltas (2 tomos, París 1837). Al morir en París, dejará dos hijos naturales, habiendo antes perdido una hija también natural. Obra madura de su pensamiento político es la Revista Política (Mora 1837: 7-299), panegírico del esfuerzo reformista protagonizado por la administración de Gómez Farías en 1833-1834. En ella, es fácil constatar cómo el liberalismo de facción asume el objetivo de transformar la sociedad para adaptarla al ideal del Estado del nuevo régimen liberal, de modo que éste deja de ser un sistema de vida política para convertirse en un ideal para la reforma social. Así, el Mora que en los años 20 había enseñado el contractualismo individualista como origen de una nación que identificaba con el Estado 
(Cf. Mora 1986:89), ahora, avanzados los años 30, afirma que con las leyes de 1833:

Lo que no se quería era, que hubiera clases ni cuerpos privilegiados, cuyos miembros estuviesen exentos de las leyes y obligaciones comunes y de la jurisdicción ordinaria: lo que no se quería era, que hubiese pequeñas sociedades dentro de la general con pretensiones de independencia respecto de ella: por último, lo que no se quería era, que los poderes sociales destinados al ejercicio de la soberania, se hiciesen derivar de los cuerpos o clases existentes, sino por el contrario, que los cuerpos creados o por crear derivasen su existencia y atribuciones del poder soberano prexistente, y no pudiesen, como los ciudadanos particulares, alegar ni tener derechos contra él. (Mora 1837: 134-135)

Lo que este liberalismo busca combatir, según Mora, es entonces la sociedad del Antiguo Régimen, compuesta por distintos cuerpos sociales con propia personalidad jurídica y peculiaridades legislativas que el Estado reconocía pero no producía; las sociedades intermedias entre el individuo y el Estado, es decir, el organicismo social, y el ordenalismo político, pues no habría de ser la sociedad la fuente del poder político, sino el Estado-poder soberano el que diera vida a la sociedad. Lo que se quiere es claramente un individualismo que permita al Estado la monopolización de la vida social por medio del normativismo: solamente tendrían derechos los individuos y no las instituciones sociales, pues éstas no serían sino instituciones estatales. Es a la luz de este estatismo como habrá de leerse la expresión de Mora: «El gobierno es el representante de la Sociedad» (Mora 1837: 232), es decir, que la sociedad no tendrá otro cauce de expresión auténtica que el Estado mismo. Con el fin de destruir la base organicista de la sociedad mexicana y poner 
las nuevas bases para su desarrollo liberal, Mora propone tres vías: atraer extranjeros anglosajones y germánicos para importar industrias y capitales, para lo cual es preciso vencer la repugnancia a la convivencia con personas de otro credo religioso; educar a los hombres públicos en las disciplinas modernas, y destruir el poder del clero en cuanto "cuerpo político», o sea público social (Cf. Mora 1837: 106-109).

Mora explica, en la «Advertencia preliminar» de sus Obras Sueltas, lo que él y los primeros liberales de facción entendían por "progreso» y «retroceso» políticos. Él identifica expresamente la «marcha política de progreso", para México, con esta serie de medidas, que son la base del programa del liberalismo de partido:

La ocupación de los bienes del clero; la abolición de los privilegios de esta clase y de la milicia; la difusión de la educación pública en las clases populares, absolutamente independiente del clero; la supresión de los monacales; la absoluta libertad de opiniones; la igualdad de los extranjeros con los naturales en los derechos civiles; y el establecimiento del jurado en las causas criminales. $(\text { Mora } 1837)^{2}$

2 «Advertencia preliminar», en Obras Sueltas de [...], ciudadano mejicano, I, París 1837, p. IV. Estos principios, con uno más y en otro orden, constituyen el índice fundamental de su Revista Política: libertad absoluta de opiniones y de prensa, abolición de los privilegios del clero y del ejército, la supresión de las instituciones monásticas y de todas las leyes que dan al clero intervención en negocios civiles (incluido el contrato de matrimonio), arreglo de la deuda pública, desamortización de la propiedad territorial y aumento del número de sus propietarios, moralización de las clases populares mediante una educación libre del monopolio del clero, abolición de la pena capital excepto en caso de homicidio premeditado y la integridad del territorio mexicano mediante una colonización acorde al carácter nacional. 
En contrapartida, la marcha política de «retroceso» es, según este pensador, la que procura abolir los pocos avances logrados en la dirección de ese progreso. Salta, pues, a la vista que lo que Mora entiende por "progreso", concretado en la aplicación de esas medidas, es fundamentalmente un proyecto de acción sobre el clero, destinado a suprimir su influjo en la sociedad. Para Mora, además, este programa reformista liberal, del que la sociedad ha de recibir su felicidad futura a través de sufrimientos presentes, habría de imponerse desde el Estado sin frenarse ante la oposición de los descontentos porque:

Cuando se ha emprendido y comenzado un cambio social, es necesario no volver los ojos atrás hasta dejarlo completo, ni pararse en poner fuera de combate a las personas que a él se oponen, cualquiera que sea su clase; de lo contrario se carga con la responsabilidad de los innumerables males de la tentativa que se hacen sufrir a un pueblo, y éstos no quedan compensados con los bienes que se esperan del éxito. (Mora 1837: 264-265)

El liberalismo reformista irrumpía en la vida política mexicana en el umbral de los ańos 30. Se comienza así la lucha del grupo o partido liberal por la conquista monopolista del Estado. Esta se producirá con el triunfo de la revolución de Ayutla en 1855 y, tras dos guerras civiles, quedará consolidada en 1867. A partir de entonces, el grupo liberal reformista tratará de dar origen a una nación nueva y liberal, principalmente mediante la difusión de su ideología a través de la educación y el monopolio de la opinión pública, una vez puesto el marco legal para apartar a la Iglesia de la vida pública de la sociedad. 
Por su parte, el conservadurismo se opone al liberalismo de facción o partido; pero sostiene el régimen político liberal como marco para el desenvolvimiento de la vida política nacional. Lejos de asumir como objetivo la transformación de la sociedad con vistas a adecuarla al modelo individualista del Estado liberal, pretende que el nuevo sistema político adoptado se desenvuelva al servicio y a la mejora presente de la sociedad ya existente. Persigue un bien común que pasa por la armonización de los intereses de los grupos sociales y que no puede prescindir de los valores o bienes culturales en los que la sociedad reconoce su propia identidad. Entre los políticos conservadores, encontraremos liberales de nuevo régimen (como Francisco Manuel Sánchez de Tagle) y antiguos tradicionalistas que aceptan sumarse al nuevo juego político (como Carlos María de Bustamante). Con el tiempo, ante la triste experiencia histórica mexicana de inestabilidad política, los conservadores, aunque sosteniendo siempre lo que el nuevo régimen liberal ofrecía de válido contra el despotismo y en pro de la libertad política y civil (como el sistema representativo, el constitucionalismo, la $\stackrel{\infty}{\neg}$ libertad de expresión de las opiniones políticas), se manifestarán contra la concepción individualista-contractualista de la nación y propondrán recuperar la concepción organicista, histórica y cultural de la misma, que procedía del horizonte tradicionalista.

El principal ideólogo conservador fue Lucas Alamán Escalada (17921853). Fue hombre cosmopolita, de una formación científica extraordinaria, de un interés humanístico, histórico y social poco común, de una larga experiencia política tanto en el gobierno como en las cámaras como en la contienda de partidos y de un sentido práctico, emprendedor, empresarial notable. Muy posiblemente fue el político, el economista y el estadista más destacado de la primera mitad del siglo XIX mexicano (Cf. Valadés 1938; Gurría 1951; González 1952; Noriega 1972: 64-101, 108:115, 289-307, 
351-356 y 363; Méndez 1996; Paoli 2002: 60-64). La evolución de su pensamiento político es representativa de la del conservadurismo mexicano en general que acabo de indicar. El artículo editorial de «El Tiempo» del 12 de febrero de 1846 (Cf. García 1965: 251-257), probablemente escrito por él, presenta el programa político del grupo conservador en una coyuntura en la que se inclinaba hacia el modelo monárquico parlamentario. Después de una introducción histórica, donde trata de evidenciar el fracaso de la república, el artículo expone los cinco deseos del grupo: un verdadero Estado, capaz de aunar libertad y orden mediante una monarquía hereditaria y un sistema parlamentario representativo; la igualdad ante la ley y el reconocimiento social según los propios méritos; un ejército ordenado, patriótico y justamente retribuido; la conservación del culto católico en su dignidad mediante el respeto a la propiedad eclesiástica de los bienes de la Iglesia, y la monarquía representativa y la estabilidad del gobierno como medios para la unidad nacional bajo un modelo centralista. En definitiva, Estado de derecho, unidad nacional mediante el centralismo, ejército capaz y respeto a los bienes eclesiásticos y a la religión. La monarquía e incluso el centralismo son propugnados sólo en calidad de medios para estos fines.

El 23 de marzo de 1853, pocos meses antes de su muerte, Lucas Alamán escribió su famosa carta a Santa Anna sintetizando el ideario de la política conservadora (Cf. Alamán 1968: 420-423; García 1965: 341-345). Parte de una concepción organicista de la nación, o sea tradicionalista, y tiene como fondo la decepción ante el nuevo régimen liberal por el fracaso de la experiencia política de los tres últimos decenios que habría terminado con la conquista norteamericana de 1847. Alamán indica seis principios que 
deberían guiar la política nacional según el partido conservador. ${ }^{3}$ El primero es la conservación de la religión católica «porque creemos en ella, y porque aun cuando no la tuviéramos por divina, la consideramos como el único lazo común que liga a todos los mexicanos, cuando todos los demás han sido rotos, y como lo único capaz de sostener a la raza hispanoamericana, y que puede librarla de los grandes peligros a que está expuesta [por la amenaza norteamericana]» (Alamán 1968: 422).

Para Alamán, la nación mexicana es aquí una comunidad histórica y no un conjunto contractualista de individuos. La constituyen las personas y los vínculos creados históricamente entre ellas. La política de los tres últimos decenios habría actuado en contra de esta sociedad, rompiendo - o dejando que se rompieran — los vínculos constitutivos de su nacionalidad. El vínculo religioso sería el único que todavía subsistiría y estaría manteniendo en acto la nacionalidad, sin el cual, ésta se perdería en provecho de la ambición expansionista de los Estados Unidos. Los otros principios que han de orientar la política según Alamán son: un poder ejecutivo fuerte y no despótico, verdadero Estado capaz de promover con eficacia el bien común de la sociedad, evitando la anarquía, y que sea Estado de derecho («sujeto a principios y responsabilidades que eviten los abusos»), evitando el despotismo; la concepción organicista de la sociedad, contra la lógica individualista del nuevo régimen liberal («contra todo lo que se llama elección popular, mientras no descanse en otras bases» no individualistas); el centralismo, contra el federalismo disolvente («una nueva división

3 Particularmente en los dos primeros hay sintonía plena con la posición de Luis Gonzaga Cuevas, otro importante intelectual y político conservador, amigo personal de Alamán (Cf. Martínez Albesa 2007: 1573-1582). Sin embargo, Cuevas no habría compartido con Alamán el monarquismo en los años 40: «El conservador Luis G. Cuevas y la crisis de la república mexicana» (Méndez Reyes 2008: 68-69). 
territorial, que confunda enteramente y haga olvidar la actual forma de Estados» para que no «retoñe» la tentación federalista); la reforma del ejército, proponiendo un ejército profesional que pueda sostenerse con los recursos estatales y la organización de una milicia de reserva muy numerosa disponible en los tiempos de guerra y no gravosa en los tiempos de paz, y la custodia eficaz de la paz interior, mediante el ejército, frente a los ataques de los indios bárbaros y a la inseguridad de los caminos.

\section{ENSAYOS Y DECEPCIONES (1835-1848)}

Como consecuencia del triunfo del plan de Cuernavaca (25 de mayo de 1834), el 4 de enero de 1835 abre sus puertas un nuevo Congreso general de mayoría centralista, que, tras pronunciamientos en diversas localidades, se autodeclarará constituyente el 9 de septiembre, reuniéndose en una sola cámara. El 3 de octubre, decretará la disolución de las legislaturas estatales, adoptando el centralismo. Dos triunfos significativos de la diplomacia mexicana de esta época fueron los reconocimientos oficiales y de la Santa Sede ( 5 de diciembre de 1836) y de España (28 de diciembre de 1836). Siete leyes constitucionales, debidas principalmente a Francisco Manuel Sánchez de Tagle (1782-1847) (Cf. Noriega 1972: 120-153; 178-180; $214-$ 223), sustituirán a la Constitución de 1824 el 29 de diciembre de $1836 .{ }^{4} \mathrm{La}$ primera ley proclama la soberanía e independencia de la nación, reconoce a la religión católica como única, señala los derechos y obligaciones de los mexicanos y habitantes y establece el sistema republicano, representativo y popular, la división de poderes y el centralismo. La segunda ley crea, con el

4 La Constitución de 1836 está publicada en Dublán y Lozano 1876: 231-257. En cierto modo, junto con las Bases orgánicas de 1843, es una cenicienta entre las constituciones mexicanas: ha recibido muchas menos publicaciones que las de 1824 y 1857. 
pesar de los santanistas, el Supremo Poder Conservador: un cuarto poder, inspirado probablemente en la monarquía inglesa, que habrá de arbitrar entre los tres clásicos, velando para que ninguno sobrepase sus competencias y para que se respete el orden constitucional; será un órgano colegiado de cinco miembros en renovación periódica. La tercera establece el sistema parlamentario bicameral. La cuarta pone el poder ejecutivo en manos de un presidente con mandato de ocho años, los ministros y un consejo de gobierno de trece miembros vitalicios. La quinta atiende al poder judicial y reconoce los fueros eclesiástico y militar. La sexta organiza un régimen centralista moderado. La séptima fija un plazo de seis años antes de que puedan hacerse reformas constitucionales. En general, estas leyes combinan bien con el liberalismo doctrinario francés y el conservadurismo inglés de la época y tratan al mismo tiempo de sacar lecciones de la agitada experiencia nacional. El ex insurgente Carlos María de Bustamante defendería decididamente este marco constitucional conservador (Cf. Bustamante 1842: 46).

El inicio de la experiencia centralista había coincidido con la crisis $\stackrel{\infty}{\neg}$ de la independencia de Texas, que provocaría un temporal desprestigio de Antonio López de Santa Anna (Cf. Vásquez 1994 y González 2003: 518733). En efecto, los colonos tejanos aprovecharon el cambio de régimen político para desconocer al gobierno mexicano en noviembre de $1835 \mathrm{y}$, en base a una serie de supuestos agravios, declararon su independencia el 2 de marzo de 1836, eligiendo a Samuel Houston por presidente y a Lorenzo de Zavala por vicepresidente. Zavala promovía el asentamiento de norteamericanos en Texas desde hacía algo más de cinco años. A finales de febrero de 1836, el general Santa Anna había llegado a San Antonio de Béjar y obtenido varias victorias; sin embargo, el 22 de abril, mientras dormía una siesta, resultó hecho prisionero en San Jacinto. Siete meses después, México recuperaría a Santa Anna, pero habría perdido Texas. La 
Guerra de los Pasteles con Francia, ya durante la presidencia de Anastasio Bustamante, brindaría al general veracruzano la oportunidad de resarcirse. El gobierno francés, haciéndose portavoz de reclamaciones de ciudadanos suyos, presentó un ultimátum al gobierno mexicano el 21 de marzo de 1838 para que entregara ochocientos mil pesos. Como México no accedió a esta reclamación, el ejército francés comenzó el ataque contra Veracruz el 27 de noviembre de ese año. La pérdida de su pie izquierdo en la defensa (5 de diciembre) devolvió a Antonio López de Santa Anna la veneración de los mexicanos. México no pudo resistir el bloqueo de sus puertos y el 9 de marzo de 1839 firmaba el tratado de paz, en virtud del cual habría de pagar a Francia seiscientos mil pesos.

Pese a las esperanzas de los conservadores, México tampoco lograría consolidarse como Estado bajo el régimen de República centralista. Las rivalidades de facciones políticas y los golpes militares continuarían. La única presidencia constitucional del nuevo orden político, que comenzó el 19 de abril de 1837, correspondió a Anastasio Bustamante y sería concluida el 30 de septiembre de 1841 a consecuencia del triple pronunciamiento de los generales Mariano Paredes Arrillaga, Gabriel Valencia y Antonio López de Santa Anna. Desde agosto de 1837, el general José Urrea y otros federalistas sembraban el norte y el oriente de sublevaciones contra el régimen. Entre marzo y julio de 1839, Anastasio Bustamante dirigió en persona una campaña militar victoriosa contra los alzados. No obstante, el 15 de julio de 1840 estallaría otro pronunciamiento federalista de Urrea y de Gómez Farías en la misma Ciudad de México, que la mantendría en vilo durante quince días. En mayo de 1839, a pocos meses del fin de la Guerra de los Pasteles, había iniciado el alzamiento yucateco que llegaría a la declaración de independencia del 1 de octubre de 1841 y, por dos años, Yucatán sería independiente. Del 25 de agosto de 1840 data una famosa carta de José María Gutiérrez Estrada 
(1800-1867) al presidente Bustamante, proponiendo la convocación de un nuevo congreso constituyente ante el fracaso de las constituciones de 1824 y 1836. Publicada el 20 de octubre, como introducción a un folleto donde se recomendaba la adopción del régimen monárquico en la persona de un príncipe extranjero, la carta suscitó gran oposición, debiendo su autor huir del país.

Desde mediados de 1839, el tema de la reforma constitucional estaba en el primer plano de la vida política. El gobierno deseaba una reforma que equivaliese a un cambio de constitución y de régimen. El Supremo Poder Conservador declaró, en noviembre de ese año, ser voluntad nacional que se procediera a la reforma constitucional sin esperar al cumplimiento del plazo de seis años, pero sin alterar las bases de libertad e independencia, religión única, sistema republicano y representativo, división de poderes y libertad de imprenta; no se salvaguardaba el centralismo. Los diputados liberales quedaron descontentos porque, además del federalismo, pretendían introducir la tolerancia de cultos. Entre 1840 y 1841, no se concretaría la reforma porque la constitución tenía demasiados enemigos en uno y otro bando político. En el agitado fin de la presidencia de Bustamante, varios proyectos se esgrimieron por el escenario político sin encontrar éxito. En definitiva, las bases de Tacubaya (28 de septiembre de 1841) acordadas por los tres generales alzados contra el régimen y el convenio de la Estanzuela (6 de octubre de 1841) entre ellos y Bustamante abrieron la capital y el país a Santa Anna y los suyos. Una junta eligió presidente provisional de la República a Antonio López de Santa Anna el 9 de octubre de 1841. La presidencia del militar veracruzano se prolongaría hasta el 12 de junio de 1843.

De todas formas, 1842 habría de ser un año de gran efervescencia política en México. Es el momento de «los vanguardistas», como ha calificado 
Israel Arroyo a los liberales protagonistas de entonces, que postularían «con posibilidad real de aprobación» «una república de individuos» de manera decidida (Arroyo García 2008: 102). Un cuarto Congreso constituyente abría sus sesiones el 1 de junio de 1842 (Noriega 1986). En él, predominaban los federalistas liberales moderados, cuyo ideólogo principal era el joven jalisciense Mariano Otero (1817-1850). ${ }^{5}$ El desacuerdo de Santa Anna con la labor del Congreso conducirá a la disolución de éste el 20 de diciembre de 1842, tras las sublevaciones de Huejotzingo y de la guarnición de Ciudad de México orquestadas por el santanista ministro de Guerra José María Tornel. Nicolás Bravo, presidente interino desde el 26 de octubre por el retiro de escena de Santa Anna a su hacienda Manga de Clavo, nombrará una Junta Nacional Legislativa de menos de un centenar de miembros para constituir a la nación. Ésta comenzaría su trabajo el 6 de enero de 1843, llegándose a la publicación de las llamadas Bases Orgánicas el 14 de junio siguiente. El contenido de este nuevo texto constitucional no era muy diverso del proyecto que el cuarto Congreso constituyente había llegado a aprobar; pero sí se distinguía en las mayores facultades que otorgaba al poder ejecutivo, en las ventajas al ejército y en la restricción de la representatividad popular (Cf. Noriega 1986: 131-173 y 175-189; De la Hidalga 2002: 138-143, 146-147 y 175-189). Santa Anna, que desde el 5 de marzo de 1843 había reasumido el ejercicio de la presidencia, quedó satisfecha.

Con la entrada en vigor de las Bases Orgánicas, inicia la segunda República centralista, que se extenderá hasta diciembre de 1845. Después de las elecciones para el Congreso, se procede a la elección del presidente

5 La obra más destacada de Mariano Otero es Ensayo sobre el verdadero estado de la cuestión social y politica que se agita en la República Mexicana (México, 1 de junio de 1842) (Guadalajara 1952). Sobre él, véase Martínez Albesa 2007: 1029-1067, Hale 1972, Reyes Heroles 1958 y Reyes Heroles 1961. 
constitucional, recayendo el nombramiento en Antonio López de Santa Anna el 2 de enero de 1844 . Solamente el 4 de junio entrará en ejercicio de la presidencia presentándose en la capital, de la que había salido en el octubre anterior. Pronto chocará con el Congreso por su proclividad al gobierno dictatorial. Con varios retiros a su hacienda, dejando el ejercicio del gobierno en otras manos, se mantendrá siempre a la expectativa. El descontento hacia sus actuaciones acabará en pronunciamientos que lo depondrán del cargo en diciembre de 1844. El general ex realista liberal moderado José Joaquín de Herrera recibió la presidencia provisional el 17 de diciembre de 1844 y, tras elecciones, se convirtió en presidente constitucional el 1 de agosto de 1845 . Tuvo en su contra a los liberales radicales y a los santanistas. El alzamiento del general Mariano Paredes Arrillaga a favor de la reunión de un congreso constituyente que pudiera instaurar un régimen monárquico provocó la renuncia de Herrera el 30 de diciembre de 1845. El ingreso en la capital de Paredes el 2 de enero de 1846 puso así fin a la segunda República centralista. Mariano Paredes asumió la presidencia interina con la intención de preparar $\stackrel{\infty}{\rightarrow}$ el cambio de régimen. Desde enero de 1846 , se publicó el periódico «El Tiempo» (24 de enero a 7 de junio de 1846), que proponía una monarquía constitucional parlamentaria y contaba con redactores como Lucas Alamán y Manuel Díez de Bonilla (Cf. Pérez Vejo 2008: 327-347).

En 1846, se precipitó el conflicto con Estados Unidos. Texas había sido admitida como Estado de la Unión norteamericana a principios del año anterior. El desacuerdo acerca del confín entre Texas y México sería utilizado por los gobernantes estadounidenses para provocar la guerra. Estados Unidos la declaró el 11 de mayo de 1846. Las tropas del general Zachary Taylor, que desde hacía más de un mes habían avanzado hasta Río Grande e incordiaban Matamoros, ocuparon esta ciudad, Monterrey y Saltillo. Las del coronel Stephen W. Kearny se posesionaron de Nuevo México y California Norte. A 
partir del 9 de marzo de 1847, las del general Winfield Scott desembarcaron por Veracruz y, a través de Jalapa y Puebla, avanzaron hasta la misma capital de la nación. La ciudad de México caía en manos estadounidenses el 14 de septiembre de 1847.

Para entonces, ya había nuevo régimen político en México; aunque no monárquico. El pronunciamiento federalista del general Mariano Salas en la Ciudad de México el 4 de agosto de 1846 (plan de la Ciudadela) había provocado el cierre del Congreso constituyente abierto el 30 de junio anterior y la proclamación de la segunda República federal mexicana (22 de agosto). El 14 de septiembre de ese año, los liberales federalistas habían recibido en triunfo a Antonio López de Santa Anna, quien regresó del destierro acompañado de Rejón, Antonio Haro Tamariz, Juan Nepomuceno Almonte (hijo natural de Morelos) y José Ignacio Basadre. Un nuevo Congreso constituyente abría sus puertas el 6 de diciembre y nombraba a Santa Anna presidente de la República y a Gómez Farías, vicepresidente. El 24 de diciembre, el presidente saldría a combatir a los norteamericanos en el norte, quedando el vicepresidente en ejercicio del supremo poder ejecutivo. Aprovechando la coyuntura de la guerra, se avanzaron leyes para desamortizar los bienes eclesiásticos. La llamada rebelión de los polkos, jóvenes reclutas, del 22 de febrero de 1847 obtuvo que Gómez Farías fuera separado del poder. Santa Anna, derrotado sucesivamente en el norte y en el este, retomaría las funciones presidenciales el 20 de mayo de ese año y organizaría la defensa de la capital, que habría de ser atacada desde el 20 de agosto. En la madrugada del 14 de septiembre, ante la inminente entrada del ejército norteamericano, Santa Anna, en Guadalupe, renuncia a la presidencia y abandona la ciudad primero y el país después. Los supremos poderes se trasladan a Querétaro. En la ciudad de México, Scott forma un ayuntamiento colaboracionista, con el liberal Francisco Suárez Iriarte al frente. 
Los meses siguientes, en Querétaro, Manuel de la Peña y Pedro María Anaya se turnan en la presidencia provisional de la República. El Congreso constituyente se clausura el 19 de noviembre de 1847, habiendo reformado la Constitución de 1824. En él, había brillado de modo especial el liberal moderado Mariano Otero, cuyo voto particular se tradujo con pocas variantes en el Acta Constitutiva y de Reformas, promulgada el 21 de mayo de 1847. Se mantenían en vigor el Acta Constitutiva del 31 de enero de 1824 y la Constitución de 1824, y, a estos documentos, se añadía el Acta de Reformas de treinta artículos (Cf. De la Hidalga 2002: 150-161).

El 2 de febrero de 1848 se firmaría el Tratado de Guadalupe-Hidalgo, ratificado en mayo, entre Estados Unidos y México. La recuperación de la libertad nacional habría de costarle a México la pérdida de unos dos millones de kilómetros cuadrados de territorio en beneficio de su vecino del norte.

\section{DE UNA GUERRA EXTERIOR A UNA GUERRA CIVIL (1848-} 1861)

Hechas las elecciones presidenciales, José Joaquín de Herrera jura como presidente constitucional el 3 de junio de 1848. Unos días después, los poderes supremos de la República regresan a la ciudad de México. El desprestigio de los militares y la conciencia de que habían fracasado tanto los gobiernos liberales como los conservadores anunciaban un período de gobierno moderado. Al amparo del mismo, no obstante, y con el cambio generacional en curso, las posiciones políticas de liberales y conservadores se radicalizarán. El 17 de agosto del mismo 1848, Yucatán, que durante la guerra se había declarado neutral, se reincorpora a la República; desde julio de 1847, se habían recrudecido en él las revueltas indígenas y, para 1849, se desataría la Guerra de Castas. También en el norte del país e incluso en 
San Luis Potosí y Querétaro, proliferarían las revueltas indígenas. Con todo, la sucesión presidencial del 15 de enero de 1851, hecha de acuerdo con la constitución, por la que el ex insurgente Mariano Arista sustituye a Herrera, da un aire de estabilidad política al periodo de 1848-1852.

El papel de la ideología en la formación de las facciones políticas, en ascenso desde 1830, llega en estos años a ser equiparable con el del personalismo y tal vez predominante (Cf. González 1977). La prensa política se hace órgano de propaganda ideológica de los partidos políticos, que precisamente ahora comienzan a mostrar cohesión en su acción y real disciplina interna, acomodándoseles bien por tanto el nombre de partidos. Los liberales contarían principalmente con los periódicos capitalinos «El Monitor Republicano», radical o puro, y «El Siglo XIX», moderado primero y radical después. El Partido Conservador (fundado en 1849) contaría sobre todo con «El Universal» en la capital del país. Durante los dos años de Arista, los liberales puros (radicales) ganan terreno en el congreso y en el gabinete gubernamental sobre los moderados. Los conservadores, que habían contado con algún ministro en época de Herrera, se ven prácticamente desplazados de la escena y denuncian en la prensa los peligros del socialismo. En este tiempo es cuando Luis Gonzaga Cuevas, destacado conservador, ministro de Bustamante y de Herrera y ahora miembro del Consejo de Gobierno, publica los dos primeros tomos de su obra Porvenir de México (México 1851 y 1952), que con el tercer tomo de 1857 , será pieza fundamental para el pensamiento conservador mexicano, remitiéndose a las tres garantías iturbidistas (Cf. Méndez Reyes 2008: 43-72). Una insurrección en Guadalajara por motivos personales y locales en el verano de 1852 sirvió de ocasión para que los santanistas invocaran el retorno de Antonio López de Santa Anna y cundiera la protesta de los conservadores contra el gobierno de Arista. Así, en esta línea, el guadalajarense plan del Hospicio (12 de octubre 
de 1852 con correcciones del siguiente día 20), con la propuesta añadida de un nuevo congreso constituyente, logra adhesiones por la mayor parte del país y, el 5 de enero de 1853, Arista renuncia a la presidencia. Tras los breves interinatos de Juan Bautista Ceballos, quien disuelve el Congreso, y de Manuel María Lombardini, nombrado para actuar los objetivos santanistas del pronunciamiento del 4 de febrero, el 17 de marzo se declara presidente a Santa Anna por medio de los votos de las legislaturas de los Estados. El siguiente día 23, Lucas Alamán escribe su carta a Santa Anna, exponiéndole las expectativas de los conservadores, cuya actuación se confiaba al mismo presidente y sus asesores, renunciando a la idea de un congreso constituyente. Santa Anna asume la presidencia el 20 de abril de 1853. Si la presidencia de Arista había significado el fracaso del moderantismo liberal, la de Santa Anna representará el fracaso del conservadurismo aliado al santanismo. En efecto, suspendido el orden constitucional de la segunda República federal, Santa Anna, en su presidencia supuestamente provisional, no tardó en iniciar un gobierno evidentemente personalista (Cf. Fowler 2008: 349-377) sin el contrapeso de un congreso y con la muerte de Lucas Alamán (2 de junio de 1853). Los líderes conservadores, decepcionados y opacados por la camarilla santanista, fueron distanciándose del presidente.

El 1 de marzo de 1854 el plan de Ayutla pone en marcha la revolución que pondrá fin al régimen de Santa Anna el 12 de agosto de 1855. Este plan, corregido en Acapulco el 11 de marzo de 1854 en un sentido abiertamente liberal, acusaba al presidente de despotismo y pedía su destitución y la convocación de un Congreso constituyente que conservara la república representativa popular. ${ }^{6}$ Rechazaba tanto el gobierno de Santa

6 Plan de Ayutla (1 de marzo de 1854) y Plan de Acapulco, modificando el de Ayutla (11 de marzo de 1854), publicados en Zarco 1956: 7-8 y 9-12. 
Anna como el cuestionamiento del régimen liberal de aquellos conservadores que volvían los ojos hacia un régimen tradicionalista. Para los paladines de Ayutla, el nuevo régimen liberal debía ser irrenunciable para la nación. Bandera capaz de atraer a los moderados y a los puros, Ayutla no presenta expresiones anticlericales; pero la serenidad de las relaciones entre el clero y el régimen santanista jugaba a favor del anticlericalismo y los liberales, una vez en el poder, harán de la Iglesia uno de los blancos de su reacción. La victoria del plan de Ayutla representa el ascenso del liberalismo de partido al poder del Estado, en un momento en que los moderantismos de ambos signos parecían tener ya poco qué ofrecer a México.

Aunque los liberales moderados conservan una presencia significativa en los gabinetes de los presidentes Juan Álvarez e Ignacio Comonfort (4 de octubre de 1855-11 de enero de 1858), serán los liberales puros quienes vayan imponiendo la orientación de estos gobiernos. El primer gabinete será predominantemente puro: Melchor Ocampo en Relaciones, Benito Juárez en Justicia y Negocios eclesiásticos, José Miguel Arrioja en Gobernación, Guillermo Prieto en Hacienda, Ponciano Arriaga en Fomento, e Ignacio Comonfort en Guerra. Tras la crisis que generó la promulgación de la Ley Juárez, de restricción del fuero eclesiástico, Álvarez deja la presidencia interina en manos de Comonfort, quien, el 13 de diciembre de 1855, forma un gobierno con liberales moderados: Luis de la Rosa en Relaciones, Ezequiel Montes en Justicia y Negocios Eclesiásticos, José María Lafragua en Gobernación, Manuel Payno en Hacienda, Manuel Silíceo en Fomento y José María Yáñez en Guerra. No obstante, múltiples cambios en el gabinete darán acceso al mismo a liberales puros como Miguel y Sebastián Lerdo de Tejada, José María Iglesias o Juan Antonio de la Fuente. El fallido pronunciamiento conservador en Zacapoaxtla (Puebla) (12 de diciembre de 1855), propiciado por el cura del lugar y luego encabezado por Antonio de 
Haro y Tamariz, dará pie al decreto de intervención del gobierno sobre los bienes eclesiásticos de la diócesis de Puebla y a la expulsión del país de su obispo Pelagio Antonio de Labastida (31 de marzo y 12 de mayo de 1856). La Ley Lerdo de desamortización de bienes eclesiásticos y otras medidas relacionadas enervan a parte de la población, produciéndose numerosos alzamientos en la segunda mitad de 1856. Destaca el levantamiento indígena de la Sierra Gorda, liderado por Tomás Mejía. A finales de enero de 1857, se dictan las leyes del Registro Civil y de secularización de los cementerios y, en abril, la Ley Iglesias, interviniendo sobre el cobro de los estipendios parroquiales. Para entonces, además, ya está en curso la polémica sobre la recién promulgada constitución, que dividirá profundamente a la nación.

El 14 de febrero de 1856 había abierto sus sesiones el Congreso constituyente, fruto de la revolución de Ayutla. ${ }^{7}$ Con el decreto de convocatoria de las elecciones para formarlo, los clérigos seculares y regulares habían quedado privados de derechos políticos. Los diputados del nuevo Congreso fueron obviamente liberales, habiendo quedado excluidos los conservadores. Terminarán su obra con la firma, sanción y juramento de la nueva Constitución el 5 de febrero de $1857 .{ }^{8}$ La comisión de Constitución estuvo formada por Ponciano Arriaga (diputado por el Distrito Federal), su principal protagonista, Mariano Yáńez (diputado por Sinaloa), Isidoro Olvera (diputado por México), José María Romero Díaz (diputado por

7 Para las referencias a las sesiones de este Congreso hemos seguido Historia del Congreso Extraordinario Constituyente (1856-1857), de Francisco Zarco (México: El Colegio de México, 1956).

8 Para un estudio más completo véase Martínez Albesa 2007. La Constitución de la República Mexicana, firmada el 5 de febrero de 1857 y promulgada el siguiente día 12, consta de ciento veintisiete artículos, puede verse en Dublán y Lozano (comps.) 1877, n. 4888: 384-399; también, y Constitución Federal de los Estados Unidos Mexicanos, sancionada y jurada por el Congreso General Constituyente, el día 5 de febrero de 1857, en ZARCO 1956: 1345-1361. 
México), Joaquín Cardoso (diputado por Oaxaca), León Guzmán (diputado por México), Pedro Escudero Echánove (diputado por Yucatán), Melchor Ocampo (diputado por Michoacán) y José María Castillo Velasco (diputado por el Distrito), y, como suplentes, José María Mata (diputado por Veracruz) y José María Cortés Esparza (diputado por Guanajuato). Su proyecto de constitución satisfizo plenamente a Arriaga, a Yáñez y a Guzmán; los demás lo firmaron con reservas, a excepción de Cardoso y Ocampo, quienes estuvieron ausentes la mayor parte del congreso, y de Olvera, que no quiso firmarlo y presentó un voto particular.

En el seno del Congreso, se discutió poco sobre las formas políticas fundamentales. El nuevo régimen liberal había sido ya adoptado en la Constitución de 1824 y no iba a ponerse en cuestión en un congreso dominado por los liberales. Reafirmado bajo la modalidad de la república federal, se acompaña ahora de una mayor adjetivación democrática en consonancia con los aires que se respiraban tras la revolución europea de 1848. La nación es concebida, por tanto, como un conjunto de individuos que voluntariamente se han asociado, dando vida a un tiempo a la sociedad civil y al Estado. Su forma política ha de descansar sobre los derechos de los individuos; de aquí, que la primera sección del primer título de la nueva constitución presente «los derechos del hombre». Conforme con su primer artículo, la Constitución de 1857 no otorga propiamente derechos, sino garantías para salvaguardar su ejercicio. Los diputados discutieron sobre cuál era el origen de estos derechos y predominó la idea de que eran prexistentes a las leyes y no derivados de estas, pese a que algunos de los liberales puros, como Ignacio Ramírez (diputado por Sinaloa) y Juan Antonio de la Fuente (diputado por Coahuila), opinaran lo contrario (Cf. Zarco 1956: 485). Tanto Ponciano Arriaga como León Guzmán sostienen la ley natural: «los derechos no nacen de la ley, sino que son anteriores a toda ley y el hombre 
nace con ellos», siendo inmutables y sagrados, como evidenciarían el derecho a la vida y el derecho a la seguridad; la ley ampararía al derecho con la fuerza a cambio del poder moral de que este la dotaría. ${ }^{9}$ Ahora bien, estos mismos conservan la lógica contractualista, aclarando que los derechos reservados, que no se sacrifican en aras de la sociedad, son derechos individuales, cuya defensa deberá hacerla el Estado frente a la misma sociedad. Este Estado liberal, señor de aquella parte de libertad natural ya sacrificada y que constituye la sociedad y custodio de la libertad individual que resta a los ciudadanos, fácilmente tenderá a concebirse como dueño de todo lo público o social y como acreedor de la libertad conservada por los individuos. El estatismo que hacía del Estado instrumento para la transformación de la sociedad estaba asimilado en el pensamiento de los liberales reformistas. En su intervención de julio de 1856, De la Fuente anota que «la constitución tiene por objeto acabar con esas instituciones ["que atacan los derechos del hombre"], que, más bien que sociales deben llamarse antisociales» (Zarco 1956: 486), y Ponciano Arriaga asegura que el «pueblo no puede ser libre ni republicano, y mucho menos venturoso, por más que cien constituciones y millares de leyes proclamen derechos abstractos, teorías bellísimas, pero impracticables, en consecuencia del absurdo sistema [...] [en acto] de la sociedad" (Zarco 1956: 387); las contradicciones sociales en los distintos campos deberían ser eliminadas por la acción del Estado. Los derechos del hombre que los diputados se proponen garantizar, según los miembros de la comisión de Constitución (Dictamen del 16 de junio de 1856), son la

9 Extracto de la intervención de Ponciano Arriaga en la sesión del 10 de julio de 1856 (Cf. Zarco 1956: 486), y Extracto de la intervención de León Guzmán en la sesión del 10 de julio de 1856 (Cf. Zarco 1956: 486-487). Véase también Dictamen de la comisión de Constitución, 16 de junio de 1856 (Cf. Zarco 1956: 306-329; 313) y Voto particular sobre el derecho de propiedad, 23 de junio de 1856, de Ponciano Arriaga (Cf. Zarco 1956: 395). 
igualdad ante la ley con abolición de fueros y prerrogativas especiales, es decir, la uniformidad de las disposiciones legales sobre todos los individuos, que dependerán inmediatamente del Estado sin mediación de instancias jurídicas intermedias; la libertad religiosa, es decir, la libertad civil de todos los cultos, compatible con la intervención del Estado sobre los mismos; la seguridad personal, bien de los individuos que justifica la existencia misma del Estado y de su poder; las garantías en todo procedimiento del orden criminal, y las garantías al derecho de propiedad privada individual (Cf. Zarco 1956: 315). Estos derechos, estrictamente individuales, se desglosarán en una lista muy completa a lo largo de veintinueve artículos constitucionales, de la que finalmente faltará sin embargo el derecho a la libertad religiosa, tal como veremos en su momento. La defensa de estos derechos, mediante la instrucción de los ciudadanos y la reforma de las viejas instituciones, es asumida como misión histórica por los liberales de partido que se han hecho con el Estado porque «el triunfo de la verdad no se ha consumado, [...] la misión de la humanidad no está cumplida, [...] la conciencia humana necesita ilustrarse»y, solamente cuando este ideal sea realidad, «será tiempo de confiar en que los derechos del hombre tendrán su expresión y su fórmula en la conciencia de todos y en la de cada uno»; mientras tanto, se impone seguir una vía progresiva, mejorar las instituciones y tener «fe en el porvenir» (Zarco 1956: 314).

Por el avance del espíritu democrático, en 1856-1857, se prefiere hablar de la soberanía del pueblo a hacerlo de la soberanía de la nación. A diferencia de lo ocurrido en 1823-1824, no encontramos definiciones de la soberanía en los debates de este congreso. Era algo que se da ya por supuesto. El principio liberal de la soberanía nacional del Acta Constitutiva de 1824 había quedado redactado en términos conciliables con la visión 
tradicionalista predominante; pero, en la Constitución ${ }^{10}$ la terminología es abiertamente liberal. La diferencia fundamental entre ambos textos es sólo un adverbio: el «radicalmente» de 1824 pasa a ser «originalmente» en 1857. El art. 39 de la Constitución de 1857, que es igual al art. 45 del proyecto de constitución, dice: «La soberanía nacional reside esencial y originalmente en el pueblo. Todo poder público dimana del pueblo, y se instituye para su beneficio. El pueblo tiene en todo tiempo el inalienable derecho de alterar o modificar la forma de su gobierno» (Zarco 1956: 1349-1350).

El «originalmente» se cierra a la consideración de la soberanía de Dios para afirmar al pueblo como origen de su propia soberanía. Además, mientras el texto de 1824 hacía soberana a la «nación», el de 1857 hace soberano al «pueblo». El artículo de 1824, más pedagógico, mencionaba a los representantes de la nación; en cambio, el de 1857, no; los sustituye por "poder público», una realidad más despersonalizada. En cierta medida, en el primero, la mención de la representación sugería una mayor vinculación de la labor de los gobernantes respecto de la voluntad de los gobernados en el ejercicio del poder; mientras que la versión de 1857 favorece más la justificación de la acción de los gobernantes, apoyada en unas legitimidades de origen y de finalidad que desdibujan la legitimidad de ejercicio. Por otra parte, el texto de la antigua acta constitutiva dejaba en manos de los representantes del pueblo la ejecución del derecho de éste a establecer y modificar leyes, mostrando un pueblo con voluntad pero sin acción; mientras que el artículo de 1857 predica del pueblo un derecho perpetuo a modificar la forma de gobierno, sin indicación alguna del medio (que sí se recogerá en el art. 41 y será en definitiva el Estado), tal vez como un modo de subrayar la

10 Constitución Federal de los Estados Unidos Mexicanos, sancionada y jurada por el Congreso General Constituyente, el día 5 de febrero de 1857. 
soberanía popular. Si el artículo de 1824 que declaraba la soberanía nacional estaba copiado de la Constitución de Cádiz, el de 1857 es una modificación del de 1824 a la luz del art. 1. ${ }^{\circ}$ de la Constitución española de 1856. Este decía: «todos los poderes públicos emanan de la Nación, en la que reside esencialmente la soberanía; y, por lo mismo, pertenece exclusivamente a la Nación el derecho de establecer sus leyes fundamentales» (Morán Martín 2000: 469).

Repitiendo lo declarado en 1824, la Constitución de 1857 otorga el carácter de soberanos a los Estados de la Federación sin que ahora los diputados manifiesten escrúpulos en la división de la soberanía. El art. 40 dice: «Es voluntad del pueblo mexicano constituirse en una república representativa, democrática, federal, compuesta de estados libres y soberanos en todo lo concerniente a su régimen interior, pero unidos en una federación establecida según los principios de esta ley fundamental» (Zarco 1956: 1350). ${ }^{11}$

Solamente al discutir el proyecto de constitución en general (sesión del 8 de julio de 1856), Luis de la Rosa, liberal moderado, criticó la aplicación de la soberanía a los Estados como algo meramente titular pero falto de realidad, porque, si se intentara dotar de soberanía efectiva a los Estados, «la soberanía producirá nacionalidades parciales» que podrán conducir a la ruptura de la nación y dar paso a la anarquía (Cf. Zarco 1956: 478). En lugar de "la nación adopta» de 1824 (art. 5. ${ }^{\circ}$ del Acta Constitutiva y art. 4. ${ }^{\circ}$ de la Constitución), ahora, en este art. 40 , se indica como sujeto al pueblo y

11 El art. 46 del proyecto de constitución decía: «Es voluntad del pueblo mexicano constituirse en una república representativa democrática federativa, compuesta de estados libres y soberanos en todo lo concerniente a su régimen interior, pero unidos en una federación establecida según los principios de esta ley fundamental para todo lo relativo a los intereses comunes y nacionales, al mantenimiento de la Unión y a los demás objetos expresados en la Constitución» (Zarco 1956: 334). 
se dice cuál es su voluntad, de acuerdo con el énfasis democrático del nuevo texto constitucional.

Los tres artículos de la Constitución de 1857 referentes a la soberanía (39, 40 y 41) se sometieron a debate y se aprobaron en una sola sesión, la del 9 de septiembre de 1856 (Cf. Zarco 1856: 832-834).

Los miembros de la comisión de Constitución habían abordado la preparación del proyecto de constitución después de preguntarse si debían limitarse «a escribir un pliego de papel más con el nombre de constitución, pero sin vida, sin raíz ni cimiento" o "cometer y herir de frente intereses o abusos [...] consolidados por el transcurso del tiempo» (Zarco 1956: 312). Solamente lo segundo se presentaba como digno de los diputados constituyentes. Nada más lejos, por tanto, de sus intenciones que el escribir una constitución que se adecuase a la constitución social de la nación tal como la encontraban. Ellos habrían de hacer una constitución para encaminar a la sociedad mexicana hacia el ideal de sociedad universalmente válida que presentaba el pensamiento liberal. Darían voz al "pueblo» mexicano, pero $\stackrel{\infty}{\neg}$ no a la sociedad mexicana. Como notó François-Xavier Guerra, llama la atención, por ejemplo, el silencio constitucional sobre las comunidades indígenas y, en general, sobre corporaciones civiles y eclesiásticas mexicanas, que quedaban desposeídas de personalidad jurídica porque «no encajan en la sociedad ideal del pensamiento liberal, fundada sobre individuos legalmente iguales y teóricamente homogéneos» (Guerra 1991: 33-34). El mesianismo calaría profundamente en la mentalidad liberal mexicana. Los liberales se sienten hombres de clarividencia superior, escogidos de entre su pueblo y enviados a rescatarlo de las lacras del Antiguo Régimen. Representantes destacados del mesianismo liberal en el Congreso fueron los liberales puros José María Mata, José María Castillo Velasco y Francisco Zarco. Mata, el 30 de julio de 1856, profesaba: «La democracia, señores, es también una religión 
que tiene sus apóstoles y sus mártires: los que aquí defendemos el progreso, aceptamos el apostolado y aceptamos también el martirio» por «los derechos y bienestar de la humanidad» (Zarco 1956: 607). La democracia deja de ser un sistema de organización política para ser más bien una verdad dogmática, aceptada como un bien irrenunciable y universal, independientemente de las circunstancias concretas que caractericen a una sociedad. Los liberales no se consideran miembros de un partido político, o sea sostenedores de una opción entre varias posibles, sino apóstoles encargados de llevar a todos los hombres el bien de una democracia cuya propagación universal culminará en la meta escatológica terrena del «bienestar de la humanidad». Y si los demás no les comprenden, por no tener su misma fe, se declaran dispuestos al martirio. Para Castillo Velasco, los diputados son de modo inmediato representantes de México; pero también en última instancia de la humanidad entera, porque la libertad que ellos auguran sería patrimonio de toda la humanidad (Cf. Zarco 1956: 569). Así, la autoridad de los liberales para sus acciones progresistas brotaría de su propia condición de conocedores del camino de la auténtica democracia; conocimiento que les da su fe en el progreso. Los liberales reformistas se sienten misioneros de una verdad universal. El hecho de considerarse en posesión de tal verdad les hace sentirse superiores. En la polémica sesión del 29 de julio, Francisco Zarco (diputado por Durango) afirma que no pueden los constituyentes «capitular» ante «las preocupaciones del vulgo» porque ellos, como legisladores, «deben ser superiores a su época»: «legislamos para el porvenir» $\mathrm{y}$ «nuestra misión es poner al pueblo mexicano en la vía del progreso» (Zarco 1956: 575). Ante la incomprensión y resistencia de quienes no comparten su fe, Zarco anima a seguir adelante: «Cuando se tiene fe, cuando se profesa un principio, es menester aceptar las reformas sin detenerse ante pequeños inconvenientes» (Zarco 1956: 575). De esta manera, la mentalidad 
liberal, lejos de replantearse la conveniencia de sus principios al constatar la oposición popular, se reafirma en ellos; dirá Mata: «todas las verdades que la humanidad ha alcanzado [...] no se han difundido sino al través de escollos y de dificultades mil», cuyas causas han sido la ignorancia o la preocupación ante la hostilidad de los otros o ante «la tendencia natural que todos tenemos a rechazar aquello que viene a chocar contra los hábitos adquiridos» (Zarco 1956: 552). Es evidente que, con estos presupuestos, los liberales mostrarán muy poca disposición para el diálogo político con quienes piensen diversamente. La misión seudo-mesiánica de los liberales reformistas les exigirá, en definitiva, no acomodarse al modo de ser del pueblo, sino por el contrario transformarlo: refiriéndose a la necesidad de corregir las expresiones «fanáticas» de la religiosidad popular y denunciando la postura conservadora, Miguel Buenrostro advierte: «Se pretende también que el Congreso se incline ante los errores y preocupaciones y respete los descarríos del vulgo [...]. Si así hubiera obrado el mismo Cristo, no habría consumado la redención» (Zarco 1956: 585-586). Por tanto, ellos vienen a $\stackrel{\infty}{\neg}$ corregir, a reformar, a cambiar. Su reforma sería terrenalmente salvífica para el pueblo, de forma que actuarían en bien del pueblo aun cuando éste los viese como enemigos. Según esta escatología terrena, el porvenir próspero estaría asegurado mediante la implantación de las reformas liberales, pese a la apariencia que tomen las consecuencias inmediatas de tales reformas, pues el mundo y la historia caminarían necesariamente hacia el liberalismo. José Antonio Gamboa (diputado por Oaxaca) advertirá a los moderados: «No queráis detener el curso del progreso, porque ninguno lo podrá conseguir» (Zarco 1956: 664); y Zarco confesará (4 de agosto de 1856): «la simiente ya está echada, ha caído en buen terreno y ella fructificará más tarde o más temprano [...] porque creo en la ley del progreso» (Zarco 1956: 678). No obstante, este futuro ideal para México podría adelantarse o posponerse 
según las opciones que se tomen; de aquí, la importancia de la labor de estos apóstoles.

El texto de la Constitución de 1857 resultó más bien liberal moderado, siendo fruto del compromiso entre las dos corrientes del partido liberal (Cf. Guerra 1991: 31-32). ${ }^{12}$ No obstante, puede decirse que dejó insatisfechos a casi todos. De una parte, los conservadores no aceptarían una constitución de cuya elaboración habían sido excluidos. De otra, los liberales puros la considerarían insuficiente en sus reformas, mientras que los liberales moderados muy pronto la juzgarían inaplicable en el agitado contexto nacional.

El conservador plan de Tacubaya contra la Constitución (17 de diciembre de 1857) triunfará en la ciudad de México el 11 de enero de 1858, donde, el día 21, su líder Félix Zuloaga será nombrado presidente interino. Desde febrero de 1859, Zuloaga vendrá sustituido por Miguel Miramón (1831-1867). El bando liberal constitucionalista, con Benito Juárez como presidente interino (por ser presidente de la Suprema Corte de Justicia cuando Comonfort deja la presidencia de la República), se sostendrá inicialmente con los contingentes de nueve importantes Estados. Los dos bandos forman por tanto sus respectivos gobiernos; el conservador se mantendrá en la capital del país y el liberal adquirirá un carácter más bien itinerante. El día 18 de enero de 1858, las tropas liberales a las órdenes de Anastasio Parrodi avanzan desde Guadalajara hacia México. Es el inicio de la Guerra de Tres Años o de Reforma, en la que liberales y conservadores se disputan la conquista del Estado.

Hasta que los liberales conquisten Zacatecas y San Luis Potosí al final de la primavera de 1858, la guerra será favorable a los conservadores.

12 Véase las páginas 29 al 58 para el estudio de la constitución. 
A partir de entonces, las hostilidades adquieren la forma de una larga guerra de desgaste para ambos bandos. La victoria de Miramón sobre Santos Degollado cerca de Querétaro del 13 de noviembre de 1859 parecería anunciar un próximo triunfo del bando conservador; sin embargo, el apoyo de Estados Unidos a los liberales habría de impedir la toma de Veracruz, sede del gobierno juarista, por los conservadores en marzo de 1860. Desde la victoria de Jesús González Ortega sobre Miramón del 10 de agosto de este año junto a Silao, comenzará a dibujarse cada vez con más nitidez el triunfo liberal, el cual efectivamente llegará tras la nueva derrota infringida por González Ortega a Miramón en las Lomas de San Miguel Calpulalpan el 22 de diciembre. El 1 de enero de 1861, el ejército constitucionalista hace su entrada triunfal en la ciudad de México y el día 10 se proclama el final de la guerra. Al día siguiente, Benito Juárez entra en la capital como presidente interino y, el 15 de junio, tomará posesión como presidente constitucional. El contexto de la guerra había dado a los liberales radicales la posibilidad de obtener lo que no habían podido alcanzar en el debate parlamentario: las

$\stackrel{\infty}{\neg}$ leyes de Reforma — decretos dictados en el verano de 1859 y en diciembre de 1860 - habían modificado sustancialmente la situación jurídica de la Iglesia en la nación.

\section{AL MONOPOLIO LIBERAL DEL PODER MEDIANTE LA GUERRA EXTERIOR Y LA CONTIENDA INTERIOR (1861-1876)}

La victoria liberal en la Guerra de Reforma trajo un clima anticatólico a la capital y a otras ciudades de la República desde el mismo enero de 1861. Incluso, en la medida en que comenzaron a aplicarse las leyes de Reforma, este clima se extendió también a zonas rurales.

Entre las primeras disposiciones de Benito Juárez, se cuentan las 
órdenes de destierro para el delegado apostólico y seis obispos, incluido el arzobispo. Con otros tres desterrados anteriormente, serían nueve los obispos fuera del país desde finales de ese mes de enero, quedando en él solamente tres: el de Durango, escondido, el de Yucatán y el vicario de Baja California. El 13 de febrero, el gobierno procedió según su criterio a reagrupar las comunidades religiosas de ciudad de México. Se suprimieron y demolieron conventos. Se redujeron de noventa y dos a cuarenta y ocho las iglesias abiertas al culto en la capital. Se dieron varios pasos para fundar una Iglesia nacional mexicana dependiente del Estado y no de la Curia romana. En los años 1861-1863, hubo jefes militares o cabecillas que en distintas localidades profanaron templos $\mathrm{y}$, esporádicamente, mataron sacerdotes. Todo esto hería los sentimientos religiosos de la población (Cf. Rivera 1890: 95-97 y 120-129; Alcalá Alvarado, coord., 1984: 227-229 y 257-258; Ramírez Aparicio 1861; Bastian 1994: 97-98; Bastian 1998: 61-70; Roeder 1958: 497; Galván Rivera 1951: 78, 91-92 y 96; Hamnett 1998: 179). Al mismo tiempo, había partidas significativas de conservadores armados que continuaban sin rendirse $y$, con el dominio de ciertas áreas y acciones de tipo guerrilla, demostraban que el país no estaba pacificado. Félix Zuloaga, Leonardo Márquez y Tomás Mejía, quien mantenía el control de la Sierra Gorda, eran los principales conservadores irreducibles. Por otra parte, entre los mismos liberales, había disensiones; unas eran personales, como la rivalidad entre González Ortega y Juárez, pero otras más profundas, como las que se daban entre el poder ejecutivo y el Congreso y entre los poderes federales y los gobernadores estatales.

El decreto juarista del 17 de julio de 1861, que incluía la suspensión de los pagos de la deuda exterior, dio pie a que Inglaterra, España y Francia acordaran intervenir en México. Diez mil soldados de las tres naciones llegan a la costa veracruzana en enero de 1862 . Tras conversaciones del ministro 
de Relaciones y Gobernación, Manuel Doblado, con el español Juan Prim y tras el arribo de un nuevo enorme contingente francés, las tropas espańolas y británicas retornan a Europa en la primera mitad de abril. Francia pretendía mucho más que garantizar la satisfacción de unas reclamaciones; buscaba constituir un gobierno monárquico en México que, como cabeza de la raza latina en América, sirviera de contención frente a los Estados Unidos, salvaguardando sus intereses en el continente. El 19 de abril de 1862, comienza la expedición militar francesa desde el Estado de Veracruz hacia la capital con el fin de derrocar al gobierno de Juárez y dar origen al Imperio de Maximiliano de Habsburgo. Se pone en curso la Guerra de Intervención. Para octubre, habría cerca de treinta mil los soldados franceses en México. El 7 de junio de 1863 toman la ciudad de México. Juárez y su gobierno huyen hacia el norte. La guerra se prolongará hasta 1867, asumiendo además el carácter de guerra civil.

Los conservadores mexicanos, durante el último decenio cada vez más decepcionados de la República y proclives a la opción monárquica, intentarían sin éxito hacer de la intervención extranjera la ocasión para introducir el gobierno conservador que la victoria liberal había impedido. La Francia de Napoleón III había decidido la intervención por iniciativa propia; no obstante el joven mexicano José Manuel Hidalgo Esnaurrízar, enterado, obtuvo del emperador de los franceses el amparo para el proyecto monárquico mexicano. Además de él, encabezaban el grupo conservador monárquico José María Gutiérrez Estrada, Juan Nepomuceno Almonte, el sacerdote Francisco Xavier Miranda y Joaquín Velázquez de León. Con el triunfo de la Intervención francesa, una asamblea de notables mexicanos había declarado, el 10 de julio de 1863, la adopción de la monarquía adjetivada como moderada, hereditaria y con príncipe católico, ofreciendo la corona imperial a Fernando Maximiliano de Habsburgo (1832-1867). El 
10 de abril de 1864, Maximiliano aceptó la corona, después de recibir los resultados favorables de un plebiscito hecho en las poblaciones dominadas por la Intervención. Habiendo asegurado el apoyo militar francés y recibido el consentimiento de su hermano el emperador austriaco y de su suegro el rey de Bélgica, se embarcó con su esposa Carlota hacia México, pasando primero por Roma para saludar al Papa. El 28 de mayo de 1864, los ya emperadores de México llegaron a Veracruz y el 12 de junio entraron en la ciudad de México.

Aprovechando la nueva coyuntura, desde septiembre de 1863, los obispos mexicanos habían comenzado a regresar a la nación. Lo habían hecho con la esperanza de que el cambio político derogara las leyes de Reforma y abriera una época de gobierno católico. Sin embargo, las relaciones de los prelados y conservadores mexicanos con los rectores de la Intervención francesa fueron tensas y conflictivas, así como también habrían de ser difíciles con el emperador Maximiliano. Las autoridades francesas procuraban una política religiosa de corte liberal, que mantuviera la libertad de cultos establecida en las leyes de Reforma y reconociera la validez de la expropiación de las propiedades de la Iglesia.

No mal recibido por el pueblo, el Imperio de Maximiliano apoyaba sobre la fuerza militar francesa, que combatía a los republicanos sostenedores del gobierno de Juárez, y sobre la esperanza de los católicos de que el monarca restableciera la libertad de la Iglesia y la catolicidad del Estado. La relación de Maximiliano con los jefes militares franceses no estuvo ausente de tensiones y además, al cabo de un par de años, la situación europea movería a Napoleón III a retirar de México a sus hombres. Las ideas liberales de Maximiliano, quien prefirió rodearse de liberales moderados que de conservadores, decepcionaron pronto a los prelados y líderes católicos, y con muchas dificultades se avanzaría hacia un acercamiento cuando ya 
el Imperio tuviera sus días casi contados. Decidido el retiro de las tropas francesas, el emperador de México se volverá hacia los conservadores en el verano de 1866, llamándoles a su gabinete de gobierno, a la prefectura de los departamentos y al Consejo de Estado. En los primeros meses de 1867, los conservadores y el Imperio unen su suerte en el intento de resistir la ofensiva de las tropas juaristas. Después de sufrir dos meses de sitio en Querétaro, Maximiliano cae en manos del enemigo el 15 de mayo de ese año. El 19 de junio siguiente, junto con Miguel Miramón y Tomás Mejía, es fusilado en el Cerro de las Campanas. Ese mismo día, la ciudad de México se rinde ante el general juarista Porfirio Díaz. Benito Juárez entra nuevamente triunfante en la capital del país el 15 de julio de 1867.

En 1867, el partido liberal obtiene la doble victoria sobre el Imperio y sobre los conservadores y conquista el Estado. La República federal continúa o reanuda su curso. A partir de este momento, los conservadores quedan excluidos de la vida política nacional. ${ }^{13}$ El poder, el Estado, será monopolio de los liberales. Sin embargo, esto no significará la llegada de $\stackrel{\infty}{\triangle}$ la paz, pues no dejarán de producirse escisiones dentro del bando liberal ni alzamientos populares contra la política gubernamental.

Algunas de estas escisiones con revueltas armadas afectarían sólo a determinados Estados, como el caso de Guerrero entre enero y abril de 1868; pero otras, al supremo gobierno de la nación, como las sublevaciones de Porfirio Díaz. Entre los alzamientos contra el gobierno federal, cabe mencionar la insurrección antijuarista del coronel Máximo Molina en Tampico (del 2 al 11 de mayo de 1871), que terminó con el fusilamiento de doscientos cuarenta y cinco militares en vísperas de las elecciones presidenciales, y la rebelión del general Jerónimo Treviño en Nuevo León,

13 Sobre el pensamiento político católico en los años siguientes, véase AdAME GodDARD I98I. 
a la que se sumó Donato Guerra en Zacatecas y otros jefes militares del norte, también contra Juárez (del 29 de septiembre de 1871 al 27 de julio de 1872). La división de los liberales en las facciones juarista, lerdista, iglesista y porfirista, si bien de contenidos principalmente personalistas, produciría también enfrentamientos armados a consecuencia de las rebeliones de Porfirio Díaz contra Benito Juárez y contra su sucesor, Sebastián Lerdo de Tejada. La rebelión porfiriana del plan de la Noria se extendió de noviembre de 1871 hasta la muerte de Juárez. La exitosa revolución constitucionalista del plan de Tuxtepec (Oaxaca) fue decidida por Díaz en septiembre de 1875. Su plan tuvo una primera versión en diciembre de ese año y se proclamó el 10 de enero de 1876 por el coronel Hermenegildo Sarmiento en Ojitlán; Díaz lo reformó el plan el 21 de marzo siguiente en Palo Blanco y el 25 de noviembre se publicó solemnemente en la ciudad de México.

No únicamente las desavenencias entre las facciones políticas liberales daban al traste con la sońada era mesiánica del liberalismo a partir de 1867 , sino que también seguirían estallando revueltas populares contra las medidas de los gobiernos liberales, sobre todo contra medidas anticatólicas de las leyes de Reforma y en favor de reivindicaciones agrarias e indígenas (Cf. Hamnett 1998: 168-185 y 172-181). En respuesta a la urgencia de las leyes de Reforma y a su adición a la constitución en el período presidencial de Sebastián Lerdo de Tejada (25 de septiembre de 1873) —aunque esta adición había sido ya propuesta por Juárez en marzo de 1871—, estalló la revolución de los «religionarios», que tomó forma a partir de la sublevación del plan de Nuevo Urecho y se extendió por Michoacán, Querétaro, Jalisco y cuatro Estados más entre 1875 y 1876 (Cf. Cosío Villegas 1955: 306311 y 329; Hamnett 1998: 169-185, 181 y 182). En cuanto a revueltas indígenas, ya con anterioridad a 1870, estaban en curso la de los yaquis y mayos en Sonora, la de Manuel Lozada y sus indígenas de Nayarit y, por 
supuesto, la Guerra de Castas de Yucatán. Junto a todo esto, el bandolerismo siguió presente en los campos y caminos del México de 1867 a 1876.

Benito Juárez conservó el poder hasta su muerte, gobernando por amplio tiempo con facultades extraordinarias a modo de dictador. De las reformas que intentó, tuvo particular éxito la educativa, que ya desde 1861 había procurado iniciar con el apoyo de quien fue entonces su ministro de Justicia e Instrucción pública Ignacio Ramírez; ahora se sirvió del positivista Gabino Barreda y comenzó por la ley orgánica de instrucción pública del Distrito Federal (2 de diciembre de 1867), que introducía la enseñanza laica y buscaba educar al pueblo en consonancia con la ideología del liberalismo, y la apertura de la Escuela Nacional Preparatoria en 1868. En unas discutidas elecciones presidenciales de 1871, Juárez logró ser relegido (12 de octubre) frente al otro pretendiente, Porfirio Díaz. No eran pocos quienes lo acusaban de apego inmoderado a la silla presidencial. Murió el 18 de julio de 1872. De acuerdo con la ley, el presidente de la Suprema Corte de Justicia Sebastián Lerdo de Tejada (1820-1889) recibió de inmediato la presidencia interina.

Ganando las elecciones, Lerdo pasó a ser presidente constitucional desde el 1 de diciembre del mismo 1872. Él lograría dar el doble paso que Juárez pretendió desde 1867 de restablecer el Senado, volviendo al sistema bicameral en el poder legislativo, frente al unicameral que la Constitución de 1857 había instituido, y de introducir el veto presidencial sobre las resoluciones del legislativo; dos medidas aprobadas el 6 de noviembre de 1873 y que suponían avances en el progresivo fortalecimiento del poder ejecutivo sobre el legislativo característico de la historia del derecho mexicano a partir de 1824. Su período debería haber concluido el 30 de noviembre de 1876, pero diez días antes hubo de abandonar la capital ante el progreso de la revolución porfiriana, a pesar de considerarse relegido en las elecciones 
del verano. El 30 de octubre de ese 1876, José María Iglesias (1823-1891), a la sazón presidente de la Suprema Corte de Justicia, declaró fraudulentas esas elecciones y se consideraría en consecuencia presidente interino de la República a partir del 30 de noviembre. Sin embargo, Porfirio Díaz (18301915) lograba hacerse con la presidencia desde el 28 de noviembre en virtud de la revolución iniciada en Tuxtepec. Iglesias, sin lograr un acuerdo con Díaz, abandonó el país en barco norteamericano entre el 24 y 25 de enero de 1877 y, el 15 de marzo siguiente, publicaría un manifiesto desde Nueva Orleáns, incitando a sus partidarios a restaurar la legalidad. Lerdo dejaba el país pocas horas después de Iglesias, pasando también a Estados Unidos. Díaz era indiscutiblemente el dueño de la situación. 


\section{BIBLIOGRAFÍA}

Adame Goddard, Jorge

1981 El pensamiento politico y social de los católicos mexicanos, 1867-1914. México: Universidad Nacional Autónoma de México, Instituto de Investigaciones Históricas.

Alamán, Lucas

1968 «Carta a Antonio López de Santa Anna (México, 23 de marzo de 1853)». En Arrangoiz, Francisco de Paula de. México desde 1808 hasta 1867. 2. ed. México: Porrúa, pp. 420-423.

Alcalá Alvarado, Alfonso (coord.)

1984 Historia de la Iglesia en América Latina. Tomo V. México: CeHILA.

Arroyo García, Israel

2008 «a arquitectura de la república mexicana, 1822-1857». En Landavazo, Marco Antonio y Agustín SÁnchez Andrés (coords.). Experiencias republicanas y monárquicas en México, América Latina y España. Siglos XIX y XX. Morelia, Mich.: Universidad Michoacana de San Nicolás de Hidalgo-Instituto de Investigaciones Históricas, pp. 73-132.

Bastian, Jean-Pierre

1994 Protestantismos y modernidad latinoamericana. Historia de unas minorias religiosas activas en América Latina. México: Fondo de Cultura Económica. 
1998 «La implantación y desarrollo del efecto de doctrina y efecto de organización en el protestantismo misional en América Latina». En Prien, Hans-Jürgen (editor). Religiosidad e historiografía. La irrupción del pluralismo religioso en América Latina y su elaboración metódica en la historiografía. Madrid: Iberoamericano, pp. 61-70.

BoCANEGRA, José María

1892 Memorias para la historia de México independiente, 1822-1846. Tomo II. México: Imprenta del gobierno federal en el exArzobispado.

Bustamante, Carlos María

1842 [1838] Análisis crítico de la constitución de 1836, en que se demuestra la injusticia y sin razón con que ciegamente, y como en tumulto o asonada se le ha censurado por escritores, que o no la han leido, o no la han entendido, y a que dio lugar el pronunciamiento que contra ella hizo el Sr. D. Anastasio Bustamante desde que tomó el mando (México, 22 de octubre de 1842). México: Imp. de Alejandro Valdés.

Cosío Villegas, Daniel (dir.)

1955 Historia moderna de México. Tomo I: La República Restaurada. La Vida Politica. México: Hermes.

Costeloe, Michael P.

1983 La primera república federal de México (1824-1835): un estudio de los partidos politicos en el México independiente. México: Fondo de Cultura Económica. [Reimpresión de la edición de 1975]. 
Cuevas, Mariano

1947 Historia de la Iglesia en México. Tomo V. México: Patria.

Dublán, Manuel y José María Lozano

1876 Legislación Mexicana o colección completa de las disposiciones legislativas expedidas desde la independencia de la República. Tomo III. México: Dublán y Lozano.

Escobar Valenzuela, Gustavo A.

1974 El liberalismo ilustrado del Dr. José María Luis Mora. México: UNAM.

FOWLER, Will

2008 «La solución desesperada: el monarquismo renuente de Antonio López de Santa Anna (1853-1864)». En Landavazo, Marco Antonio y Agustín SÁnchez Andrés (coords.). Experiencias republicanas y monárquicas en México, América Latina y España. Siglos XIX y XX. Morelia, Mich.: Universidad Michoacana de San Nicolás de Hidalgo-Instituto de Investigaciones Históricas, pp. 349-377.

Galván Rivera, Mariano

1950[1951] Colección de las Efemérides publicadas en el Calendario del Más Antiguo Galván desde su fundación hasta el 30 de junio de 1950. México: Antigua Librería de Murguía. 
García Cantú, Gastón

1965 El pensamiento de la reacción mexicana. Historia documental, 18101962. México: Empresas editoriales.

Guerra, François-Xavier

1991 México: Del Antiguo Régimen a la Revolución. Tomo I. México: Fondo de Cultura Económica.

GonzÁlez Navarro, Moisés

1952 El pensamiento político de Lucas Alamán. México: El Colegio de México.

1977 Anatomía del poder en México (1848-1853). México: El Colegio de México.

Gurría Lacroix, Jorge

1951 Las ideas monárquicas de don Lucas Alamán. México: Instituto de Historia.

Hale, Charles A.

1972 El liberalismo mexicano en la época de Mora (1821-1853). México: Siglo XXI.

HamnetT, Brian R.

1998 «La Iglesia católica en México y el desafío liberal, 1855-1876. Aspectos metodológicos e historiográficos», En Prien, HansJürgen (editor). Religiosidad e historiografía: la irrupción del pluralismo religioso en América Latina y su elaboración metódica en la historiografia. Madrid: Iberoamericana, pp. 169-185. 
Hidalga, Luis de la

2002 Historia del Derecho constitucional mexicano. México: Porrúa.

Martínez Albesa, Emilio

2007 La Constitución de 1857. Catolicismo y liberalismo en México. 3 tomos. México: Porrúa.

MÉndez Reyes, Salvador

1996 El hispanoamericanismo de Lucas Alamán (1823-1853). Toluca: Universidad Autónoma del Estado de México.

2008 «El conservador Luis G. Cuevas y la crisis de la república mexicana». En Landavazo, Marco Antonio y Agustín Sánchez ANDRÉs (coords.). Experiencias republicanas y monárquicas en México, América Latina y España. Siglos XIX y XX. Morelia, Mich.: Universidad Michoacana de San Nicolás de Hidalgo-Instituto de Investigaciones Históricas, pp. 43-72.

Mora, José María Luis

1837 Revista Política de las diversas administraciones que la República Mejicana ha tenido hasta 1837. En Obras sueltas de José María Luis Mora, ciudadano mejicano. Tomo I. París: Rosa.

Noriega, Alfonso

1972 El pensamiento conservador y el conservadurismo mexicano. México: Universidad Nacional Autónoma de México. 
Noriega Elío, Cecilia

1986 El Constituyente de 1842. México: Universidad Nacional Autónoma de México, Instituto de Investigaciones Históricas.

Otero, Mariano

1952 Ensayo sobre el verdadero estado de la cuestión social y politica que se agita en la República Mexicana (México, 1 de junio de 1842), Guadalajara: Ediciones I. T. G.

Paoli Bolio, Francisco José

2002 Conciencia y poder en México. Siglos XIX y XX.

México: Porrúa.

PÉrez Vejo, Tomás

2008 «Las encrucijadas ideológicas del monarquismo mexicano en la primera mitad del siglo XIX». En Landavazo, Marco Antonio y Agustín SÁnchez Andrés (coords.). Experiencias republicanas y monárquicas en México, América Latina y España. Siglos XIX y XX. Morelia, Mich.: Universidad Michoacana de San Nicolás de Hidalgo-Instituto de Investigaciones Históricas, pp. 327-347.

Ramírez Aparicio, Manuel

1861 Los conventos suprimidos en México. Estudios biográficos, históricos y arqueológicos. México: Innovación. 
Reyes Heroles, Jesús

1958 El liberalismo mexicano. Tomo II: La sociedad fluctuante. México: Facultad de Derecho, Universidad Nacional Autónoma de México.

1961 El liberalismo mexicano. Tomo III: La integración de las ideas, México: Facultad de Derecho, Universidad Nacional Autónoma de México.

Rivera, Agustín

1890 Anales Mexicanos. Tomo I. La Reforma y el Segundo Imperio. Lagos: Tipografía de Vicente Veloz.

Roeder, Ralph

1958 Juárez y su México. Tomo II. México: Universidad de Indiana.

VAladÉs, José Carlos

1938 Alamán. Estadista e Historiador. México: Antigua librería Rebredo; J. Porrúa e hijos.

VÁzQuez, Josefina Zoraida (coord.)

1994 De la rebelión de Texas a la Guerra del 47. México: Nueva Imagen.

Zarco, Francisco

1956 Historia del Congreso Extraordinario Constituyente (1856-1857). México: El Colegio de México. 